\title{
PREPAREDNESS OF PREGRADUATE STUDENT NURSES TO PRACTICE THEIR PROFESSION IN CRÈCHES
}

\section{Gergana V. Markova, Evgeniya K. Dimitrova ${ }^{1}$}

\author{
Department of Surgical Nursing, \\ Medical University - Pleven, \\ Bulgaria \\ ${ }^{1}$ Department of Therapeutic Care, \\ Medical University - Pleven, \\ Bulgaria
}

\section{Summary}

Nursing degree courses in Bulgaria provide a wide range of career opportunities to graduates. These opportunities, however, do not solve the current problems of the healthcare system. This communication presents the results of a survey conducted among graduate students majoring in the nursing specialty at the Medical University in Pleven. The survey aimed to acquire information on the graduates' willingness to practice in nurseries. A questionnaire containing 26 questions specially designed for the study was used. The data were processed with statistical software packages Statgraphics; SPSS v. 19 and Excel for Windows. Despite the sound theoretical and practical course of training, 13 $(21.67 \%)$ of the students were embarrassed, and 13 said they had been cautious when they first entered a crèche during their training. Almost half of the respondents -29 (48.33\%) reported that they might work in a creche only if it is necessary, and $16(26.66 \%)$ - never. Only $9(15.00 \%)$ declared they would be committed to caring for children aged one to three years. At the end of their training, student nurses did not feel sufficiently prepared for the psychological and pedagogical challenges to practice their profession in such child day care centers. The respondents had no clear idea of the role of the nurse in a crèche. Very few of the student nurses reported a willingness to work in a crèche.

Key words: crèche, student nurse, motivation

\section{Introduction}

Healthcare in Bulgaria faces many problems and challenges, ranging from underfunding and improper spending to lack of both motivated staff and staff shortages. All this inevitably leads to deterioration of nursing care quality. These problems also affect crèches, which are part of the healthcare system in the country. According to Art. 2.(1) of Regulation No 26 of 18 November 2008 on the structure and activities of creches and creche kitchens and health requirements for them, nurses are mostly employed in these establishments. One of the goals of UNICEF in Bulgaria is oriented to creating conditions for every child to receive quality health care [1]. For this purpose, nurses should have 
the necessary professional training. The nursing practice involves personality capabilities, and training and working experience develop professional ones [2-6]. According to Lebikyan et Vassileva (2009), exercising the nursing profession requires competencies to identify the health needs, and the physical, mental and social risks for their patients (children in this case). They should be able to recognize the health problems of the patients and make a nursing diagnosis. Nurses have to be responsible for their professional development; possess the knowledge and skills for planning and organizing health care in crèches. Within the scope of their competences, nurses should be responsible for the nursing care they provide [7]. To this date, the training course for nurses in Bulgaria is comprehensive [8], providing a wide range of opportunities for the professional realization of graduates. However, professional training alone cannot solve the current problems.

It is known that there is a lack of health professionals in active young age in health establishments, and this holds true about crèches in Pleven municipality. Tatyozov et Pravchev (2008) are also of the opinion that there is an outflow of personnel from children's prophylactic institutions [9]. Although according to Veleva et al. (2013), the reason is not lack of nurses in general. Instead, there is no motivation for practising the profession in general [10]. According to M. Draganova (2016), lack of nursing staff is one of the major obstacles to improving the health system. Further studies are needed to obtain a better overview of the motivation of nurses to practice their profession and the factors that determine the lack of motivation [11].

The study aimed to determine the readiness of students nurses, graduating from the Medical University - Pleven to practice in crèches.

\section{Materials and Methods}

The study was carried out using sociological methods (documentary method and survey method) and statistical methods for description and analysis of the data collected.

The study was conducted in two stages. The first stage was carried out in the 2016/2017 academic year and included 30 student nurses before their graduation. The second stage took place in the 2016/2017 academic year and another group of 30 students about to graduate.

A documentary method was applied to study the literature and analyse the syllabus for training nurses at the Medical University - Pleven.

We used a questionnaire containing 26 questions and specially designed for the study. The questionnaire was approved by the Commission on Ethics in Research at the Medical University - Pleven (№344/ 20.02.2015). Each of the respondents could answer the questions at his/her convenience, and then drop the anonymously completed forms in a special box.

The data was processed with statistical software packages Statgraphics; SPSS v. 19 and Excel for Windows. The results are presented in tables, graphics and numeral indicators for structure, frequency, average data, and correlation coefficients.

\section{Results}

The study included 60 student nurses: 53 (88.33\%) females and $7(11.67 \%)$ males. They were all graduates who had completed their practical training and pre-graduation internship in a creche (Figure 1).

In compliance with the state requirements, the theoretical training of student nurses

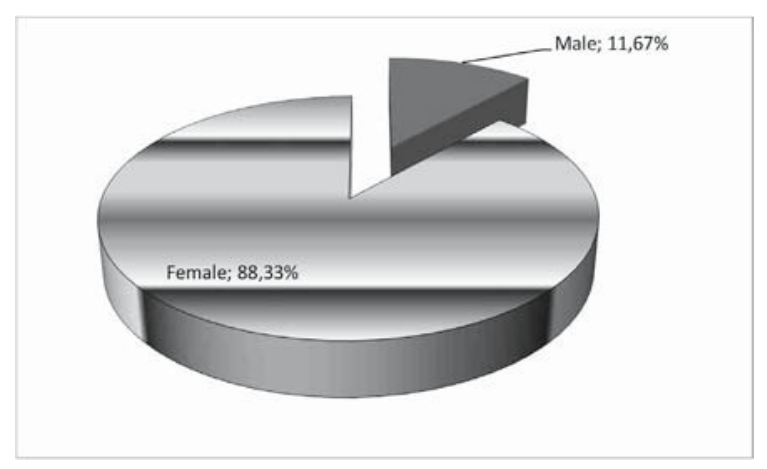

Figure 1. Distribution of the students by gender (\%, $\mathrm{n}=60$ )

includes subjects such as children pedagogy and child psychology, paediatrics with neonatology, and health promotion. In addition to the above listed compulsory courses, student nurses at the Medical University - Pleven have the opportunity to acquire further knowledge on the workflow in crèches by taking an optional course on duties of nurses in upbringing children in a creche. They also have a chance to acquire practical skills during the practical training and a 
pre-graduation internship in a creche (Table 1).

Nearly one third - $19(31.67 \%)$ of the students stated that during their first entry into a creche they felt confident in their knowledge and

Table 1. Subjects studied by student nurses at Medical University - Pleven

\begin{tabular}{llll}
\hline Discipline & Semester & \multicolumn{2}{l}{ Hours (classes) } \\
\cline { 3 - 4 } & & L & E \\
\hline Theoretical preparation & & 26 & 4 \\
Children's pedagogy and psychology & I & 10 & 5 \\
The obligation of a nurse in raising and educating children & II & 41 & 4 \\
Pediatrics & IV & 10 & 5 \\
Health promotion & V & & \\
Clinical preparation & & 24 & \\
Practice in a crèche & II & 36 \\
Practice in a crèche & IV & 120 \\
Before graduate practice & VII/VIII & \multicolumn{2}{c}{10} \\
\hline
\end{tabular}

skills to work in such an environment. However, despite the solid theoretical and practical training, 13 students (21.67\%) were worried, and the same number felt a lack of confidence. Slightly more than one-third of the respondents $-22(36.66 \%)$ defined professional training to work in a creche as fully sufficient, 18 (30.00\%) - as insufficient, and $9(15.00 \%)$ had no definite judgment. The respondents, who stated that at the end of their pre-graduate internship, their professional training had been insufficient, felt confident and calm when first entering a creche. There was a significant correlation relationship $\left(\chi^{2}=52.26 ; \mathrm{df}=28\right.$; Cramer's V=0.46; $\left.\mathrm{p}=0.004\right)$. Respondents were able to identify what they lacked in professional training for effective and anxiety-free work in crèches. Slightly more than one-half - $32(53.33 \%)$ answered the question. For 25 (78.12\%) of the respondents, pedagogical and psychological preparations were insufficient to exercise their profession in crèches. According to the rest of the respondents - 7 students $(21.87 \%)$, the practical preparation had been insufficient.

Nearly half of the respondents - $29(48.33 \%)$ stated that they might work in a creche only if it were highly necessary, and $16(26.66 \%)-$ never. Only $9(15.00 \%)$ declared they would be committed to caring for children attending a crèche.

Students were given an option to argue why they would not work in crèches, but only 32 people responded (Figure 2).

There was a significant difference between those who would and who would not be willing

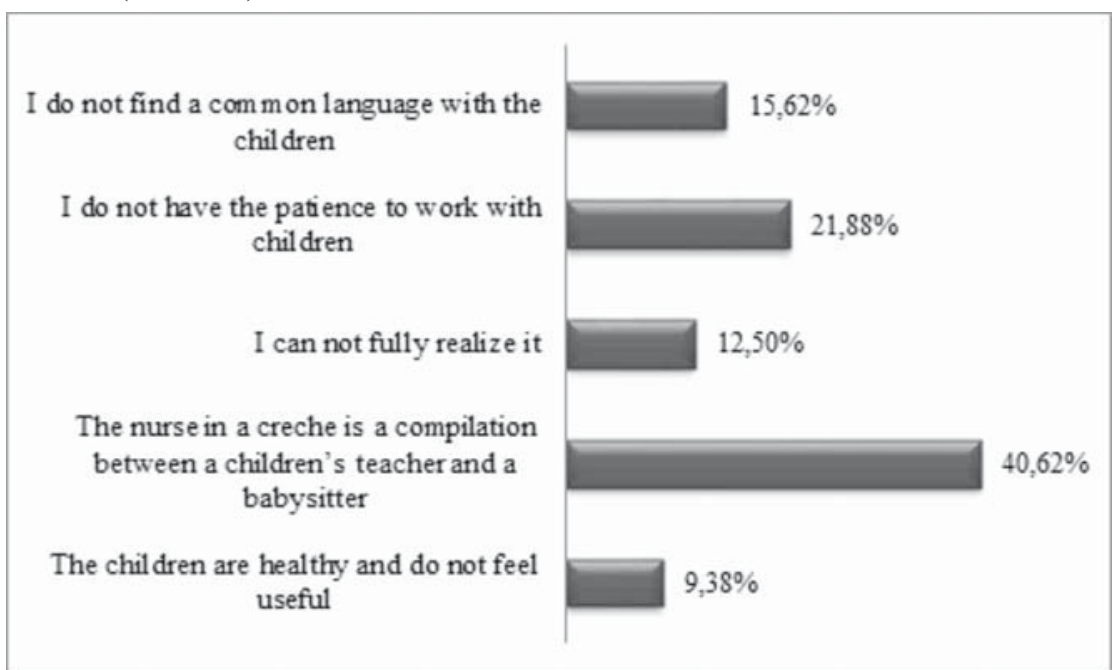

Figure 2. Distribution of the students by their motives to do not want their professional realization to be in crèches 
to work in crèches. Their self-evaluation of the level of professional preparation $\left(\chi^{2}=7.53\right.$; $\mathrm{df}=12$; Cramer's $\mathrm{V}=0.56 ; \mathrm{p}=0.001)$ and those of their reasons $\left(\chi^{2}=65.15 ; \mathrm{df}=33\right.$; Cramer's $\mathrm{V}=0.60 ; \mathrm{p}=0.001$ ) had a significant influenced on their choice.

\section{Discussion}

The training courses for nurses at the Medical University - Pleven are organized following national and European standards. These courses include disciplines that are meant to enable a student to acquire theoretical knowledge and practical skills specific for working with children in crèches.

During their first entry in crèches, the students included in the study were confident and relaxed. This is due to the lack of sufficient knowledge and experience, and our results confirmed it. However, at the end of their training, after the students had acquired knowledge and formed skills and habits, some of the respondents believed that their preparation was not sufficient to practice the profession with confidence in this sector of healthcare. By admitting this fact, the students demonstrated responsibility and selfcriticism. They claimed they lacked pedagogical and psychological knowledge and skills to work with children attending crèches (1-3 years old). The problem of insufficient knowledge and skills has long been stated by student nurses in other universities as well. This view was supported by L. Peneva (2011). According to her, there is a deficit of actual, adequate in volume and content psychological-pedagogical knowledge and skills in Bulgaria among the majority of medical professionals working in crèches [12].

Another problem that determines the willingness of students to work in a creche is the idea of practicing the profession in this department of health. Students think that the position of a nurse in a crèche combines working as a nanny and a teacher in a kindergarten. The lack of a clear idea of practicing the profession in a crèche poses a problem that needs to be addressed. During the training, there should be a focus on the role of a nurse as an educator and health promoter in a crèche, among other roles. As a result of the problems defined, the respondents expressed little or no motivation to work in crèches. The problem is growing because very soon the staff currently employed in crèches will have to be replaced by a new generation of nurses. The lack of health professionals is more than evident.

The lack of sufficient preparation and the opinion about the profession demotivate the graduate students and affect negatively their willingness to work in these health establishments.

\section{Conclusions}

At the end of their training, after completing the training course and acquiring theoretical knowledge and practical skills, student claim they need more pedagogical and psychological skills to practice their profession in crèches. The graduates have no clear idea of the role of nurses in the creche. There is almost no one of the new university graduates who want to work in these health-prophylactic institutions.

In conclusion, we can say that future health specialists need additional pedagogical and psychological training to become more confident when working with children in a crèche. During their training at the university, the role of nurses working in crèches should be elucidated. Measures should be taken to make nursing in a crèche more attractive to newly graduated nurses.

\section{Acknowledgements}

This study has no financial support.

\section{References}

1. UNICEF. [Early childhood development. Bulgaria, 2013]. Bulgarian. [cited 2019 Mar 14].Available from: https://www.unicef.bg/ mobile/bg/themes/view/slug/31

2. Atanasova Z, Miteva K. [Role Playing - a prerequisite for mastering communicative skills and patterns of behaviour among medical professionals]. Science and Technologies. 2011;1(1):229-33. Bulgarian.

3. Dimitrova E. [Formation of professional qualities in nursing students in the process of clinical training.]. Health Care.2006;4:24-7. Bulgarian. 
4. Jeleva F. [Methodology of training on Health Care and formation of professional competences of the future healthcare professional. Scientific papers of the University of Rousse. 2016;55(8.1):106-10. Bulgarian.

5. Miteva K. [The process of training to build the professional competencies of medical professionals]. Sisterhood.2011; 1-2:47-51. Bulgarian.

6. Serbezova I. [Professionally essential values of the medical specialists and their formation.]. Scientific papers of the University of Rousse. 2010;49(8.1):30-5. Bulgarian.

7. Lebikyan E, Vasileva P. [The Competences of Nurses in the Changing Modern Society]. Scientific papers of the University of Rousse. 2009;48(8.1):150-2. Bulgarian.

8. Ordinance of the uniform state requirements for the higher education of nurses, midwife and medical assistant for bachelor academic degree. State Gazette. 2016 Apr 22.

9. Tatyozov T, Pravchev V. [Organizational and health problems in crèches]. Pre-school education. 2008; 1:6-8.

10. Veleva N, Draganova M, Vekov T, AlexandrovaYankulovska S, Grancharova G. Bulgarian nursing workforce forecast (2013-2025). Eur J Public Health. 2013;23(1):242-3.

11. Draganova M. [Motivation of nurses - an important element in the management of health care.] Management and Education. 2016; 12:138-141. Bulgarian.

12. Peneva L. [Early Childhood Education and Care - European Priorities and Bulgarian Reality.] Pre-school education. 2011;7:2-5. Bulgarian. 